\title{
Masked repetition priming: Lexical activation or novel memory trace?
}

\author{
KENNETH FORSTER, JLL BOOKER, and DANIEL L. SCHACTER \\ University of Arizona, Tucson, Arizona \\ and \\ CHRISTOPHER DAVIS \\ Monash University, Clayton, Victoria, Australia
}

\begin{abstract}
Are priming effects in implicit memory tasks produced by changes in lexical activation or by the formation of an episodic memory trace of the prime? If the latter view is correct, then no priming should be observed if subjects are unaware of the priming stimulus. Four experiments are reported in which the effect of a masked priming word upon subsequent performance on stemand fragment-completion tasks was examined. Strong and consistent effects were observed in both tasks when there was a short delay $(1 \mathrm{sec})$ between the presentation of the prime and the test item, but at longer delays $(20 \mathrm{sec})$, these effects appear to have dissipated. These results are consistent with the lexical activation view. However, they are also compatible with the view that a masked prime generates a special type of memory trace that is inaccessible to conscious awareness and is extremely short-lived. It is argued that further evidence is required to decide between these alternatives.
\end{abstract}

The speed with which a word can be processed appears to be increased if that word has been recently encountered. This phenomenon was first discovered in the context of the lexical decision task, where it was shown that repeated words produced faster and more accurate decision times on the second presentation (Forbach, Stanners, \& Hochhaus, 1974; Scarborough, Cortese, \& Scarborough, 1977). In addition, it has been shown that tachistoscopic identification accuracy is also facilitated by repetition (Murrell \& Morton, 1974; Jacoby \& Dallas, 1981).

This repetition effect has attracted a great deal of attention in two allied, but separate, fields of cognitive psychology. In the psycholinguistic literature, where language perception is the focus of interest, the phenomenon was originally interpreted as a change in the lexical processing system. That is, the perceptual processing triggered by the first encounter with a word was assumed to leave the lexical representation of that word in an active state, so that when the second presentation of that word occurs, the lexical representation is more accessible. We shall refer to this type of explanation as a lexical activation account. On the other hand, for experimental psychologists interested primarily in memory, what was intriguing about the effect was that it occurred even though subjects were unable to decide whether or not the word had recently been encountered. Indeed, even profound amnesics showed clear repetition effects, which implied that the lexical decision task accesses stored information about the

Correspondence may be addressed to Kenneth Forster, Department of Psychology, University of Arizona, Tucson, AZ 85721. original encounter that is inaccessible to normal retrieval mechanisms (Schacter, 1987, 1990).

Subsequent work showed two things. First, the repetition effect lasted much longer than one would expect lexical activation to persist-estimates up to several days and even longer were not uncommon (Jacoby, 1983; Tulving, Schacter, \& Stark, 1982). Second, it began to become apparent that the strength of the effect depended on circumstances of the original encounter that had little to do with the process of lexical activation. For example, the repetition effect for words presented in the context of another word was greater if the original context was reinstated on the second testing occasion (Carroll \& Kirsner, 1982). Furthermore, it was found that the repetition effect can be very weak if the subject is not required to make some specific task-relevant response to the first presentation (Forster \& Davis, 1984, Experiment 4; Oliphant, 1983). Such effects led many investigators to reject the lexical activation account of repetition effects, and to propose instead that the repetition effect is somehow produced by the episodic memory trace of the first encounter, even though the strength of this trace is insufficient to support accurate old-new decisions (e.g., Feustel, Shiffrin, \& Salasoo, 1983; Jacoby, 1983). We shall refer to this type of explanation as an episodic memory interpretation.

Forster and Davis (1984) attempted to eliminate any episodic contamination by masking the priming stimulus so that subjects were unable to report its identity. The assumption was that no episodic record is kept of stimuli that escape awareness, and hence any repetition effect obtained under these conditions was more likely to reflect pure lexical activation. Under these conditions, a strong 
repetition effect for lexical decision was in fact obtained, which differed from the standard nonmasked effect in three respects. First, it was very short-lived (less than $2 \mathrm{sec}$ ), as one might expect of a lexical effect. Second, it was also the case that the masked effect was independent of word frequency, whereas the standard, nonmasked repetition effect was not. Finally, no effects were observed for nonword targets.

The purpose of the research reported here was to investigate more carefully the basic assumption of the Forster and Davis (1984) procedure-namely, that any priming effects observed with masked primes must be lexical activation effects. Is it really the case that masking the prime prevents any trace formation? Could it be that a masked prime leaves behind a special type of memory trace that is accessed when the target word is presented, but is otherwise inaccessible? If this is so, then might it not be this trace that produces the priming effect, and not lexical activation?

A memory trace having some of these properties has been postulated by Schacter (in press). His proposal is that the standard (nonmasked) repetition priming effect is due to the construction of a special perceptual record of the prime in what is called the "word-form system" (Warrington \& Shallice, 1980)-a specialized memory subsystem devoted to words that constitutes part of a more general perceptual representation system (Schacter, Cooper, \& Delaney, 1990; Tulving \& Schacter, 1990). The word-form system is potentially distinguishable from the lexicon in that its records include information specific to the actual circumstances of the original event (e.g., case information), whereas the lexicon contains only highly abstract records. A record in the word-form system has no episodic tags (i.e., has no information about when the experience occurred), and is therefore inaccessible in normal tests of episodic memory. It follows from this account that subjects would also never be directly aware of the existence of the record.

Schacter (in press) makes no assumption that masked primes would necessarily generate records in the wordform system, nor does he specifically assume that wordform records are prelexical. However, the proposal outlined here is clearly an interesting possible extension of that account. In this view, we could say that the effect of the mask in the Forster and Davis (1984) paradigm is simply to eliminate the formation of an explicit episodic record of the prime. It does not necessarily prevent the formation of a record in the word-form system.

But how would this proposal explain the fact that the masked repetition effect lasts such a brief time, as shown by Forster and Davis (1984)? One possibility is that longlasting repetition effects in the lexical decision task are only produced by the combined effects of an episodic trace and a word-form record, as would be the case if the prime were not masked. But in the absence of any episodic trace, the word-form record alone is incapable of sustaining long-lasting lexical decision effects. However, such effects might be detected if we use tasks that are more sen- sitive to the existence of the word-form record. The best candidates would obviously be the tasks typically used in studies of implicit memory, such as stem completion or fragment completion.

The research program described below was designed to investigate this hypothesis by establishing whether masked priming effects occur in stem- and fragmentcompletion tasks, and if so, what their duration might be. Based on the assumption that the effect of a masked prime is just to increase lexical activation temporarily, we might expect to find priming effects with completion tasks only to the extent that the word-retrieval mechanisms involved are the same as those involved in lexical decision. Furthermore, such effects should be short-lived, as shown by Forster and Davis (1984) for the lexical decision task. If, on the other hand, a masked prime is capable of establishing a word-form record, then we might expect to find effects at much longer delays.

The idea of looking for masked priming effects with completion tasks was initially suggested by Davis (1986). His experiment suggested that such effects could be obtained with the stem-completion task with very short delays. The first experiment we report here was designed simply to confirm that finding. The subject was presented with the sequence of stimuli shown in Figure 1. The first word in the sequence is a dummy word that is designed only to provide a forward mask for the second word, the prime, which was presented for $60 \mathrm{msec}$. The next word intervened between the prime and the target, and served mainly to backward mask the prime, and also to prevent the possibility that the letters of the prime were still available when the test item was presented. Finally, the test item always consisted of the first three letters of a word, and there were always at least two possible completions available. Upon presentation of the test item, subjects were asked to write the first completion they thought of, there being no constraint on the length of the completion. If priming occurs, then subjects will be more likely to write down ELASTIC (as opposed to, say, ELATED) when elastic was the prime compared to a baseline condition in which the prime was some other word totally unrelated to the test item (e.g., lattice).

A third condition was included in which the prime was related to the target solution in form (differing by one letter), but the prime was not in fact a possible completion. For example, in the above example, a form-related prime would have been the word plastic. Since it is known that form-related priming occurs with masked primes (Forster, 1987; Forster, Davis, Schoknecht, \& Carter, 1987),

\begin{tabular}{|cccc|}
\hline stomach & elastic & almanac & ELA -.-> \\
mask & prime & intervening & test \\
$500 \mathrm{~ms}$ & $60 \mathrm{~ms}$ & $500 \mathrm{~ms}$ & $1500 \mathrm{~ms}$ \\
\hline
\end{tabular}

Figure 1. Stimulus sequence used in Experiment 1. 
we know that in lexical decision the prime plastic will cross-activate the entry for elastic, thereby making responses to this word faster. If the masked prime functions in the same way in the stem-completion task, then a similar effect should occur.

The first experiment involved 60 items. Three sets of materials were constructed, so that each item was tested in all three conditions. A total of 15 subjects were used. Stimuli were presented on a computer-controlled video display.

The results of this experiment were clear-cut. The percentage of trials on which the masked prime was used as the completion was $32.7 \%$, compared with the baseline rate of $14.4 \%$. This difference was significant by min $F^{\prime}$, and is comparable in magnitude to the effects normally reported in the implicit memory literature. This result confirms Davis's (1986) findings, and shows that a masked prime influences not only lexical decision, but also stem completion. In addition, clear cross-activation effects were observed, since in the form-related condition there was a significant tendency for completions related in form to the prime to be given (27.4\%). That is, elastic was given more often as a response to ELA --->, even when the masked prime was plastic.

These results are clearly compatible with a lexical account of priming. In such an account, the masked prime alters the accessibility of the lexical entry for the prime, so that a subsequent retrieval operation attempting to find a possible completion is more likely to recover the entry for the prime. Thus, the lexical retrieval operations involved when only the first three letters are presented (as in stem completion) might be primed in much the same way as when the entire word is presented (as in lexical decision). The existence of cross-activation effects also suggests that much the same process must be involved in both tasks.

However, this lexical account becomes less plausible as the retention interval over which priming effects can be demonstrated increases. Accordingly, the next experiment was designed to test the limits of the effect. Instead of a mere $500 \mathrm{msec}$, the retention interval was increased to approximately $20 \mathrm{sec}$. The test items were exactly the same as those in Experiment 1, except that on half of the primed trials, the prime had actually been presented four items previously. That is, on trial $N$, the masked prime elastic might be presented, but the relevant test item ELA ---> would not be presented until trial $N+4$. Since subjects typically take about $5 \mathrm{sec}$ to respond to each item, this produces a retention interval of approximately $20 \mathrm{sec}$. The remaining primed trials used the same 500 -msec interval used in Experiment 1.

The results of this experiment also seem reasonably clear. Once again, with the 500-msec interval used in Experiment 1 , we obtained a higher completion rate in the primed condition $(33.8 \%)$ than in the baseline condition (13.8\%). However, with four intervening items, the primed condition (17.2\%) no longer differed significantly from baseline. This result suggests that the masked prim- ing effect dissipates rapidly for the stem-completion task as well as for the lexical decision task, as originally shown by Forster and Davis (1984). Hence, a lexical interpretation of both effects still seems viable.

We have argued that performance in stem completion might be mediated by the same word-retrieval operations as those used in lexical decision (and normal reading). This seems reasonable, since the first three letters of a word represent a fairly powerful stimulus, and it is not hard to imagine that a retrieval mechanism could reliably find a word that began with a specified three letters. But for fragment completion, this is not the case (at least with the single-completion fragments used by Tulving et al., 1982 , and others since). Many of these fragments produce no completion at all for several seconds, and some may never produce a satisfactory completion without priming. It might therefore be proposed that successful performance here is not mediated by the word-retrieval operations discussed above (otherwise, a solution would be immediately available), but instead is mediated by some kind of problem-solving mode of processing, rather than a simple perceptual mode. Hence, one might not expect to find any masked priming effects in a fragment-completion task, whatever the delay.

Experiment 3 was designed to test this hypothesis. It was an exact parallel of Experiment 2, except that the stem-completion items were converted to fragmentcompletion items (e.g., ELA---> became E_AS_IC). The baseline rate of completion for these items was $24.8 \%$. For the 500-msec delay condition, the completion rate was $44.3 \%$, which differed significantly from baseline. However, for the four-trial delay condition, the completion rate $(30.5 \%)$ did not differ significantly from baseline, although there was an obvious trend in this direction.

These data provide evidence against the hypothesis that fragment completion does not show masked priming effects, at least for the short-delay condition. The longer delay condition produced ambiguous results, and unfortunately this is the condition that we would like to rest our argument on. Accordingly, we decided to extend the delay considerably in a follow-up experiment, in the hope that this would either make the effect dissipate altogether, or make it clear that there was still a weak effect even at long delays.

Experiment 4 used a two-phase design. In Phase 1, subjects received 105 items for lexical decision. Embedded within these trials were masked primes. For example, a typical item in Phase 1 might have been: \#\#\#\#\#-parcels-PIGMENT, where the first stimulus is the forward mask, the second is a masked prime, and the third is a target item for lexical decision. In Phase 2, the subjects carried out a fragment-completion task. These fragments were based on a masked prime from Phase 1, a target word from the lexical decision task in Phase 1, or some other word not previously shown in the experiment. Thus, the fragment $P_{-} G_{-} M_{-} T$ is primed by a seen target word in the above example (i.e., PIGMENT), 
whereas the fragment $P_{-}-C_{-} S_{\text {is }}$ is primed by a masked prime (pieces). Finally, the fragment _ YD_AN _ is a baseline item (i.e., its completion, HYDRANT was not presented at all). All subjects received the same set of fragments in Phase 2, but they received one of three different sets of materials in Phase 1, so that each fragment was observed in all three conditions.

The baseline completion rate in this experiment was $21.5 \%$, which was slightly higher than the completion rate in the masked prime condition (20.0\%). Therefore we can be confident that in a two-phase design with an interval of approximately 15-20 min between the prime and the target, there is no priming effect when the prime is masked. However, when the prime was not maskedthat is, when the prime was a target word in Phase 1 (e.g., pigment)-the completion rate was $45.2 \%$, which was a highly significant effect compared with the baseline.

The fragments used in this experiment were those originally used by Tulving et al. (1982), and it is known that normal priming effects with these items last at least a week, if not longer. So why did the effect observed in this experiment with masked primes decay so quickly? One possible answer is that masking weakens the effect, so that it decays more rapidly. An argument against this, however, is that the effect at the short delay was just as strong as the effect typically found with nonmasked primes.

One plausible account is that the short-term effect in all tasks is in fact a lexical activation effect, which takes place whether or not the prime is masked. Since it is a lexical effect, it exhibits cross-activation and it dissipates rapidly. However, long-term effects require some additional mechanism, such as the formation of a word-form record of the prime, but this requires that the prime be consciously perceived.

To make this interpretation work, we need to assume that fragments elicit normal lexical retrieval operations. Since these operations are usually designed to minimize the occurrence of familiar letter clusters, this seems unlikely. This hypothesis has been directly investigated by Johnston (1989), who tested whether fragments were capable of priming lexical decisions. If a fragment engages normal lexical retrieval mechanisms, then we might expect a masked presentation of the fragment $p_{-} g m_{--} t$ to facilitate lexical decision responses to its completion PIGMENT. This was not the case, although masked presentations of stems did produce a significant priming effect.

This result suggests that fragments alone do not automatically access the appropriate lexical entry: However, this is not to say that augmented fragments might not have this capacity. Such augmentation could result from deliberate trial-and-error attempts by the subject to discover some of the missing letters, especially those that are more critical for access. In the example cited above, attempts might be made to access to an entry using

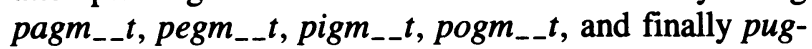

$m_{-\_} t$. Given this filling-in strategy, it does not seem at all unlikely that the entry for pigment would eventually be retrieved, and hence there is a possible lexical locus for a priming effect.

To explain these results using a nonlexical site for priming, we would have to postulate a word-form record (or something like it) that lasts only a very short time for a masked stimulus but has a long duration if the stimulus is not masked. From the point of view of parsimony, there is not much to differentiate between this account and the proposal made here, namely that there are different sites for the two effects-a lexical site for very short-term effects with masked stimuli and a nonlexical for the longterm effects.

There is, however, an additional source of evidence that helps to discriminate between these competing accounts. The nonlexical interpretation assumes that the same process is involved in both short-term and long-term effects; all that changes is the duration of the record. It follows from this account that we should not find dissociations between the two types of priming. That is, we should not be able to find a task that shows one kind of priming but not the other.

The semantic categorization task appears to be one task that has this property. In this task, a subject is given a semantic property and is then asked whether a test item refers to an object that possesses that property. Such a task shows a clear masked priming effect (Forster, 1985, Experiment 5). In that experiment, the test items had to be classified according to whether they referred to objects that were bigger than a brick. These items were immediately preceded either by a masked presentation of the same word in different case or by a completely different word. Categorization times were faster when the two words were the same, regardless of whether the correct answer was "Yes" or "No." This result can be explained on the assumption that the masked prime activates the lexical entry for the test item, thereby making it more accessible.

However, the categorization task apparently does not show long-term repetition effects with normally presented primes. An unpublished experiment carried out by the first author found no significant long-term repetition effects for the "bigger-than-a-brick" categorization task. That experiment used a between-tasks design, with lexical decision in the first phase and categorization in the second phase. Similarly, Monsell (1985) found no long-term repetition priming for a semantic categorization task (nice/nasty). The priming task used in the first phase of that experiment was that of syntactic categorization.

These results create difficulties for the view that shortterm and long-term repetition effects are mediated by the same mechanisms. One plausible explanation of this difference rests on the following argument. The basis for the long-term effect in lexical decision is an increase in the familiarity of the stimulus produced by the memory trace of the previous encounter with the priming stimu- 
lus. If the subject appreciates that words are more likely than nonwords to be remembered, then it follows that a familiar stimulus is more likely to be a word than a nonword. However, this increase in familiarity is irrelevant in the semantic categorization task, since there is no way that familiarity can assist category-membership decisions (e.g., the test item "dog"' is no more likely to belong to the category ANIMAL simply because it seems familiar). However, masked repetition effects are still observed with this task because this effect is a genuine lexical effect, which means that the relevant semantic properties of the item "dog" are made available more rapidly to the decision-making system.

To summarize, we have demonstrated that masked priming effects can be obtained with both stem- and fragment-completion tasks. These effects appear to be of limited duration, as has been found previously with the lexical decision task. This result is most compatible with a purely lexical interpretation of masked priming, in which the prime briefly alters the activation level of a lexical entry so that subsequent retrieval operations are more likely to access that entry. Longer term priming effects, we feel, are more likely to be mediated by nonlexical sources, such as the word-form system postulated by Schacter (in press). Although this system represents information about prior occurrences of lexical items, it retains information about the physical form of the stimulus, and hence is more a perceptual record of the occurrence rather than a linguistic representation of it.

\section{REFERENCES}

Carroll, M., \& Kirsner, K. (1982). Context and repetition effects in lexical decision and recognition memory. Journal of Verbal Learning \& Verbal Behavior, 21, 55-69.

DAvis, C. (1986). [Masked priming with the stem-completion task.] Unpublished data.

Feustel, T. C., Shiffrin, R. M., \& Salasoo, A. (1983). Episodic and lexical contributions to the repetition effect in word identification. Journal of Experimental Psychology: General, 112, 309346.

Forbach, G. B., Stanners, R. F., \& Hochhaus, L. (1974). Repetition and practice effects in a lexical decision task. Memory \& Cognition, 2, 337-339.
Forster, K. I. (1985). Lexical acquisition and the modular lexicon. Language \& Cognitive Processes, 1, 87-108.

FORSTER, K. I. (1987). Form-priming with masked primes: The bestmatch hypothesis. In M. Coltheart (Ed.), Attention and performance (Vol. 12, pp. 127-146). Hillsdale, NJ: Erlbaum.

Forster, K. I., \& DAvIS, C. (1984). Repetition priming and frequency attenuation in lexical access. Journal of Experimental Psychology: Learning, Memory, \& Cognition, 10, 680-698.

Forster, K. I., Davis, C., SChoknecht, C., \& Carter, R. (1987). Masked priming with graphemically related forms: Repetition or partial activation? Quarterly Journal of Experimental Psychology, 39A, 211-251.

JACOBY, L. L. (1983). Perceptual enhancement: Persistent effects of an experience. Journal of Experimental Psychology: Learning, Memory, \& Cognition, 9, 21-38.

JACOBY, L. L., \& DALLAS, M. (1981). On the relationship between autobiographical memory and perceptual learning. Journal of Experimental Psychology: General, 110, 306-340.

JoHNSTON, M. B. (1989). Lexical and implicit memory processes in stem and fragment completion tasks. Unpublished Honours Thesis, Monash University, Clayton, Victoria, Australia.

Monsell, S. (1985). Repetition and the lexicon. In A. W. Ellis (Ed.), Progress in the psychology of language (Vol. 2, pp. 147-195). London: Erlbaum.

Murrell, G. A., \& Morton, J. (1974). Word recognition and morphemic structure. Journal of Experimental Psychology, 102, 963-968.

OLIPHANT, G. W. (1983). Repetition and recency effects in word recognition. Australian Journal of Psychology, 35, 393-403.

Scarborough, D. L., Cortese, C., \& Scarborough, H. S. (1977). Frequency and repetition effects in lexical memory. Journal of $E x-$ perimental Psychology: Human Perception \& Performance, 3, 1-17.

SCHACTER, D. L. (1987). Implicit memory: History and current status. Journal of Experimental Psychology: Learning, Memory, \& Cognition, 13, 501-518.

SCHACTER, D. L. (1990). Introduction to "Implicit memory: Multiple perspectives." Bulletin of the Psychonomic Society, 28, 338-340.

SCHACTER, D. L. (in press). Perceptual representation systems and implicit memory: Toward a resolution of the multiple memory systems debate. In A. Diamond (Ed.), Development and neural bases of higher cognitive function. New York: Annals of the New York Academy of Sciences.

SChacter, D. L., CoOper, L., \& Delaney, S. (1990). Implicit memory for unfamiliar objects depends on access to structural descriptions. Journal of Experimental Psychology: General, 119, 5-21.

Tulving, E., Schacter, D. (1990). Priming and human memory systems. Science, 247, 301-306.

Tulving, E., Schacter, D. L., \& Stark, H. A. (1982). Priming effects in word-fragment completions are independent of recognition memory. Journal of Experimental Psychology: Learning, Memory, \& Cognition, 8, 336-342.

Warrington, E. K., \&hallice, T. (1980). Word-form dyslexia. Brain, 103, 99-112. 